\title{
FINITE ELEMENT ANALYSIS OF VENTILATION SYSTEM FIRE DAMPER DYNAMIC TIME-HISTORY
}

\author{
Dariusz Skibicki \\ Łukasz Pejkowski \\ Michał Stopel \\ UTP University of Science and Technology, Poland
}

\begin{abstract}
The paper presents results of the numerical analysis of the fire damper used in ventilation systems under the earthquake loading. The research was conducted in accordance with the recommendations of the Nuclear Safety Standards Commission. The aim of the analysis was to examine the fire damper with respect to its resistance to service loadings, structural integrity, and capability to stay operative after an earthquake. The analysis was carried out using the Finite Element Method in LS-Dyna software. The earthquake loading was modelled as accelerations, measured in three directions during the earthquake. For modelling of the materials behaviour, material models taking into account the influence of strain rate on hardening were used. The analysis consisted of three stages, which were: loading the construction with the earth gravity, earthquake simulation by loading with accelerations in three directions, and, finally, closing the fire damper. The analysis has shown that some of the construction elements undergo plastic deformations. However, the performed simulation of fire damper closing showed that despite these deformations, the device remains capable to keep its functionality and the damper closes hermetically. The results of the analysis were important design indications for the fire damper prototype.
\end{abstract}

Keywords: fire barriers, earthquake, finite element method

\section{INTRODUCTION}

It is estimated that in the years 2000-2006, the fire was the cause of $5 \%$ of ship accidents [1]. Fire dampers are key elements of structural fire protection of buildings, offshore facilities or ships. They play the role of fire barriers, but also protect against toxic hazard. In the initial phase, the airconditioning system can cause uniform distribution of toxic concentrations [2].

Correct operation of this kind of installation depends on taking into account different general types of loadings at the design stage, such as fatigue loadings for instance [3, 4]. Especially for offshore drilling tower construction types, the following types of loadings are listed in the NORSOK standard: impact loads caused by explosion or ship collision, and loads caused by extreme weather or earthquake [5].

Like other constructions, the fire barriers are not $100 \%$ reliable [6]. For this reason, it is very important to take into account detailed engineering data regarding materials properties and loadings which construction may undergo in the design process. Moreover, an engineer should be equipped with computational methods able to predict the construction's behaviour in extreme conditions. Furthermore, it is desired that using these methods can take into account the postulate of the Damage-Tolerant design strategy, which assumes the possibility of machine usage with an existing damage [7]. 
According to the idea of this strategy, fire safety elements should keep the ability to reliable task realization even in case of damage or high plastic deformation. Such damages can be the result of explosion or earthquake.

The computational method which can be used to simulate construction's behaviour in real loadings conditions, taking into account degradation of the construction, is the Finite Element Method (FEM) [8-10]. The aim of this work was to test the ventilation channel fire damper prototype in earthquake loading conditions using the FEM method. Using the computer simulation, the strength, stability and suitability of the damper for emergency use in case of earthquake was investigated. The analysis results have made the basis for indicating possible modifications of the fire damper prototype.

\section{ANALYSIS PROGRAMME}

The fire damper analysis programme was designed on the basis of "Design of Nuclear Power Plants against Seismic Events; Part 4: Components" [11]. This standard was selected by reason of exceptionally detailed research guidelines and high safety standards. Due to the fact that the present research is a numerical research, the standard guidelines given in point 3.3.1.a and concerning the verification by analysis were taken into account particularly. Based on these guidelines, the following research scheme was assumed:

1) determination of excitation in the place of installation,

2) modelling and determination of model parameters,

3) analysis of mechanical behaviour,

4) verification of limit conditions.

As for point 1, the seaside area of Turkey, which is particularly prone to earthquake danger, was selected. With accordance to the option given in Point 4.4.1.1.b of the standard [11], entitled "Time History Method", a real history of accelerations recorded in three directions was selected. The data was acquired from the USGS Earthquake Hazards Program database, available on the website [12]. According to the computational procedure assumed on the basis of [13], the recorded acceleration histories were modified to fit the target design spectra. For this purpose, two design spectra were used. They were prepared using the procedures described in $[11,14]$ and the data achieved from [15]. The adjustment of the recorded acceleration histories to the design spectra was performed using the Direct Scaling method [13].

As for point 2, the construction of the analysed fire damper was modelled using the FEM method and LS-DYNA software. It is a general-purpose explicit FE code capable of nonlinear dynamic analysis for 3D structures. The choice of the software was made taking into account that LS-DYNA is an ANSI/ ASME NQA-1 (nuclear quality assurance) certificated code and is widely used in the nuclear power industry, usually to analyse seismic responses. The numerical model was prepared using the LS-PREPOST software, which was also used for elaboration of results.
As for points 3 and 4, the analysis of mechanical properties and the verification of boundary conditions was divided, in accordance with [11], into 3 areas:

1) investigation of resistance to service loadings (results of the gravity and damper closing process) and loadings being the result of the earthquake, that is the strength and stability analysis,

2) investigation of structural integrity, that is the analysis of possible occurrence of large deformations and leakage,

3) investigation of fire damper capability to stay operative after the earthquake.

Within point 1 ), the calculated values of maximum equivalent stresses were compared to limit values, such as yield stress and ultimate tensile strength for the applied materials. Within point 2), possible presence of large and irreversible deformations of the fire damper was checked, along with their impact on sealing. Within point 3), the ability of fire damper to close in 20 seconds after the earthquake, which was required by the manufacturer, was checked. The analysis results for points 1) and 2) are presented in Chapter 5.1 and for point 3) in Chapter 5.2.

\section{DETERMINATION OF LOADING AT THE PLACE OF INSTALLATION}

The calculations considering the impact of earthquake made use of the acceleration histories for the strongest earthquake in the history, registered on the area of Turkey. The data, given in Tab. 1, was collected from the USGS Earthquake Hazards Program website [12]. The acceleration was recorded in three directions: $N$ - north, $E$ - east, and $Z$ - vertical (Fig. 1).

Tab. 1. Earthquake data recorded for the area of Turkey

\begin{tabular}{|c|c|}
\hline Latitude & $40.756^{\circ} \mathrm{N}$ \\
\hline Longitude & $29.955^{\circ} \mathrm{E}$ \\
\hline Date & $1999-08-1700: 01: 38 \mathrm{UTC}$ \\
\hline Depth & $17.0 \mathrm{~km}$ \\
\hline Magnitude & Mw7.4 \\
\hline
\end{tabular}

The time histories were modified using the Direct Scaling method in order to fit them to the target design spectra determined in accordance with the European standard KTA 2201.4 [11]. The spectrum of the time histories was also compared to the target design spectra determined on the basis of the American standard ASCE 7-95 [14]. The target design spectra according to KTA 2201.4 were performed on the basis of parameters determined in the harmonic analysis of the recorded signal and the standard [11] recommendations. The calculated values of parameters required for the spectrum performing are given in Tab. 2.

The target design spectra according to ASCE 7-95 were performed using the data obtained from [15]. The determined parameters used to create the design spectrum are given in Tab. 3. 
The target design spectra prepared according to the European KTA 2201.4 standard [11] and the American standard ASCE 7-95 [14], are shown in Fig 2 a and b, respectively. The amplitude-frequency signal characteristics of the selected earthquake, determined using the Fourier transformation, are put on the charts.

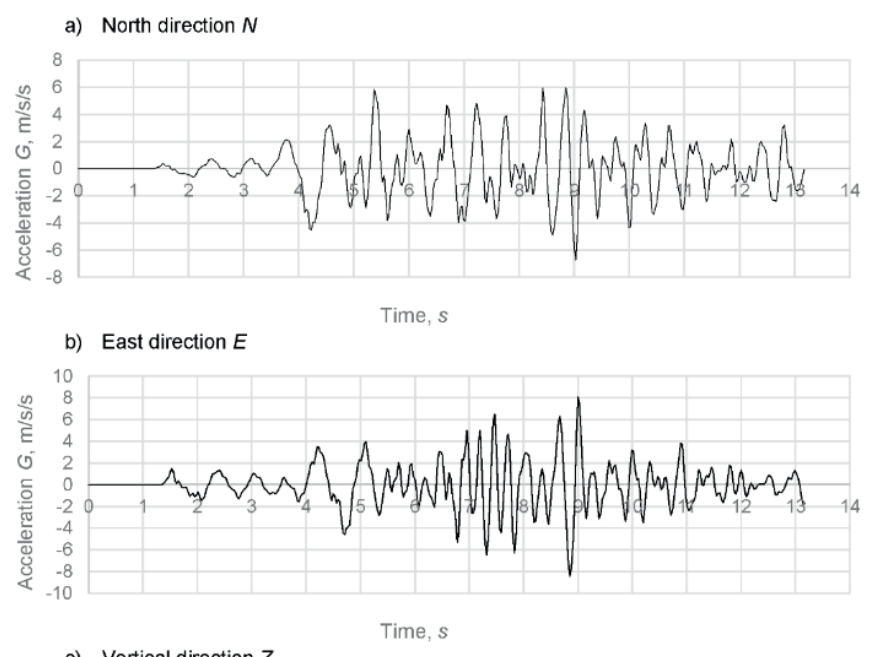

Vertical direction $Z$

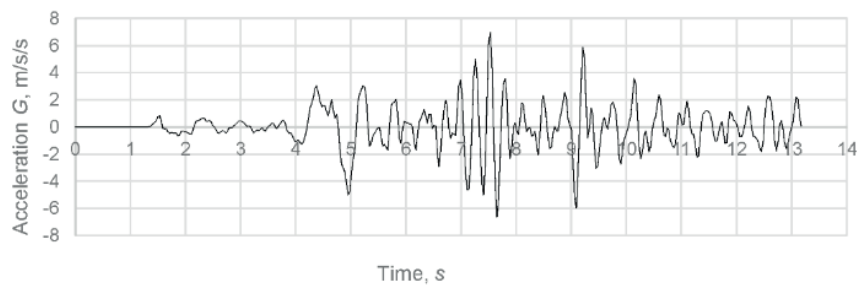

Fig. 1. Time histories of the strongest earthquake recorded on the Turkey territory, accelerations in three directions

Tab. 2. Target design spectrum parameters according to KTA 2201.4

\begin{tabular}{|c|c|c|}
\hline 1) & $\begin{array}{l}\text { Lowest decisive eigenfrequency of the } \\
\text { major system at the lower limit value in the } \\
\text { variation range of system parameters }\end{array}$ & $\begin{array}{c}f_{1}=0.5 \mathrm{~Hz} \\
0.8 f_{1}=0.4 \mathrm{~Hz}\end{array}$ \\
\hline 2) & $\begin{array}{l}\text { Highest decisive eigenfrequency of the } \\
\text { major system for the upper limit value in the } \\
\text { variation range of component parameters }\end{array}$ & $\begin{array}{c}f_{n}=8 \mathrm{~Hz} \\
1.2 f_{n}=9.6 \mathrm{~Hz}\end{array}$ \\
\hline 3) & $\begin{array}{l}\text { Upper limit frequency of the response } \\
\text { spectrum of the major system }\end{array}$ & $f_{\text {limit }}=20 \mathrm{~Hz}$ \\
\hline 4) & $\begin{array}{l}\text { Acceleration of the major system } \\
\text { (component) at the place of installation of } \\
\text { the subsystem, }\end{array}$ & $a_{g}=1.1 G$ \\
\hline 5) & Spectrum amplification factor & $v=8$ \\
\hline
\end{tabular}

It is almost impossible to achieve response spectra of the recorded accelerograms equal to the design spectra, since the design spectra are based on the medians of numerous different time histories [13]. However, comparing the amplitude-frequency characteristics with the model spectra allows for the conclusion that the character of the selected earthquake does not deviate from typical earthquakes recorded in the selected region.

\section{MODELING AND DETERMINATION OF PARAMETERS}

\section{GEOMETRICAL MODEL}

The construction model was divided into 24 parts, connected using contacts (Fig. 3). The parts which are immobilized relative to each other were connected using bonding contacts (CONTACT_TIED_SURFACE_TO_SURFACE), while parts which form kinematic pairs were connected using contacts which allow for mutual movement including friction (CONTACT_AUTOMATIC_SURFACE_TO_SURFACE). In total, the model consisted of 2291 elements. Large and flat surfaces were modelled using shell type elements (ELEMENT FORMULATION 2). Parts of the lever system composing the damper opening mechanism were modelled using beam type elements (ELEMENT FORMULATION 1) (Fig. 3.c). Solid type elements (ELEMENT FORMULATION 1) were used to model parts of the rotary node (Fig. 4).

Tab. 3. Target design spectrum parameters according to ASCE 7-95

\begin{tabular}{|c|c|c|}
\hline 1) & $\begin{array}{l}\text { The values of basic } \\
\text { parameters: } S_{s} \text { (Short Period } \\
\text { Spectral Acceleration) and } \\
S_{1} \text { (1-sec Period Spectral } \\
\text { Acceleration) which are } \\
\text { typical for the Turkey } \\
\text { region were selected: }\end{array}$ & $\begin{array}{l}S_{S}=1.65 G \\
S_{1}=0.75 G\end{array}$ \\
\hline \multirow[t]{2}{*}{ 2) } & $\begin{array}{l}\text { The following amplification } \\
\text { coefficients were chosen: }\end{array}$ & \\
\hline & $\begin{array}{l}\text { a) Amplification } \\
\text { Coefficient for } S_{s}-F_{a} \\
\text { and site Amplification } \\
\text { Coefficient for } S_{1}-F v \text { : }\end{array}$ & $\begin{array}{c}F_{a}=1 \\
F_{v}=1.5\end{array}$ \\
\hline & $\begin{array}{l}\text { b) Spectral response } \\
\text { acceleration }\end{array}$ & $\begin{array}{c}S_{M S}=F_{a} S_{S}=1.65 G \\
S_{M 1}=F_{v} S_{1}=1.125 G\end{array}$ \\
\hline & $\begin{array}{l}\text { c) Designed earthquake } \\
\text { spectral response } \\
\text { acceleration parameters }\end{array}$ & $\begin{aligned} S_{D S} & =-\frac{3}{3} S_{M S}=1.1 G \\
S_{D 1} & =\frac{2}{3} S_{M 1}=0.75 G\end{aligned}$ \\
\hline 3) & Calculated time parameters & $\begin{array}{c}T_{0}=0.2 \frac{S_{D 1}}{S_{D S}}=0.14 \mathrm{~s} \\
T_{S}=\frac{S_{D 1}}{S_{D S}}=0.68 \mathrm{~s}\end{array}$ \\
\hline 4) & $\begin{array}{l}\text { Calculated spectrum } \\
\text { parameters }\end{array}$ & $T=\left\{\begin{array}{cc}T<T_{0} & S_{a}=S_{D S}\left(0.4+0.6 \frac{T}{T_{0}}\right) \\
T_{0} \leq T<T_{s} & S_{a}=S_{D S} \\
T \geq T_{s} & S_{a}=\frac{S_{D 1}}{T}\end{array}\right.$ \\
\hline
\end{tabular}
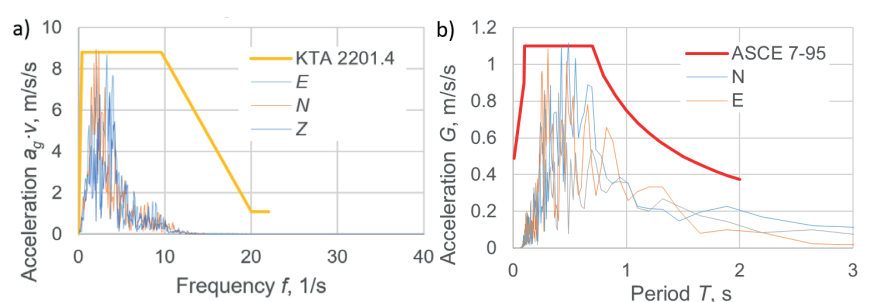

Fig. 2. Loading spectrum 
a)

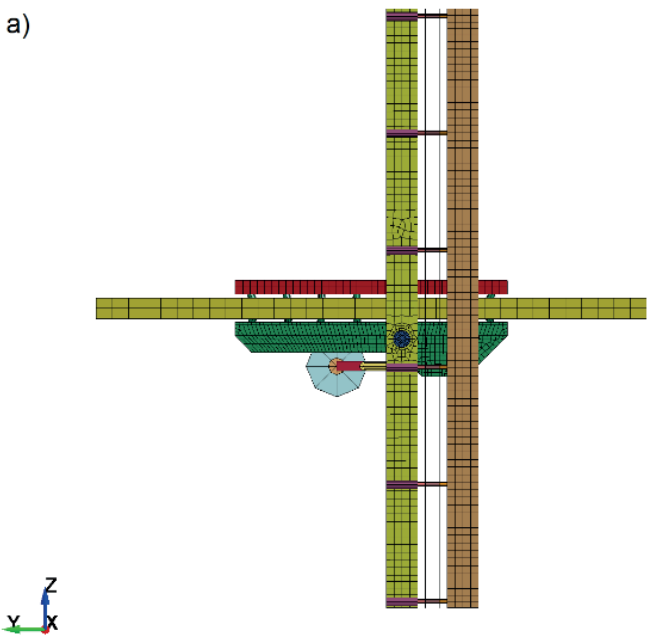

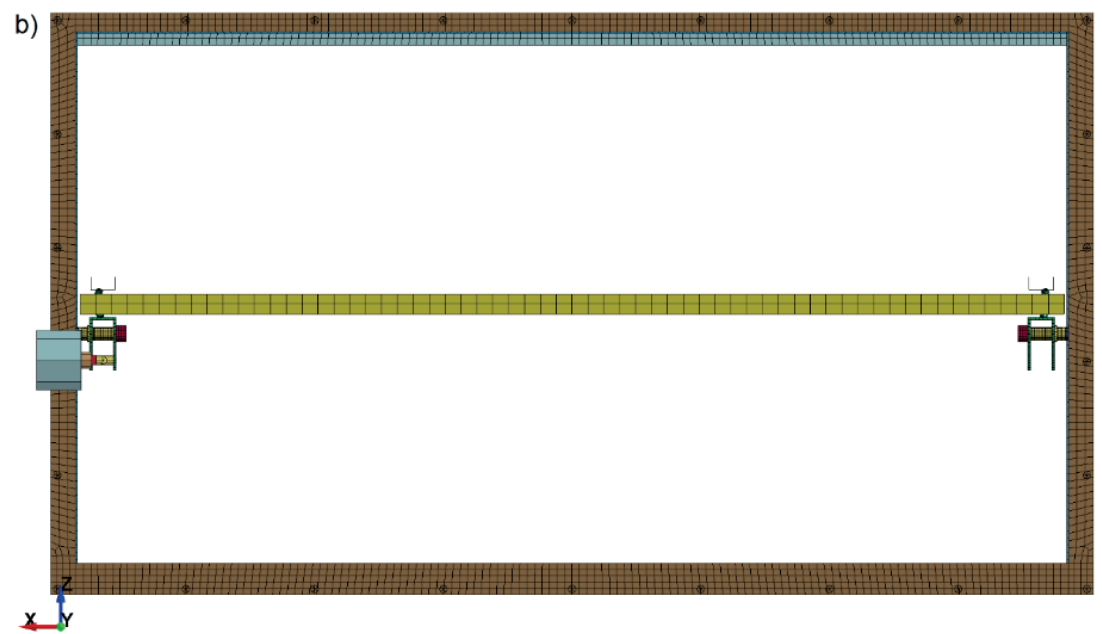

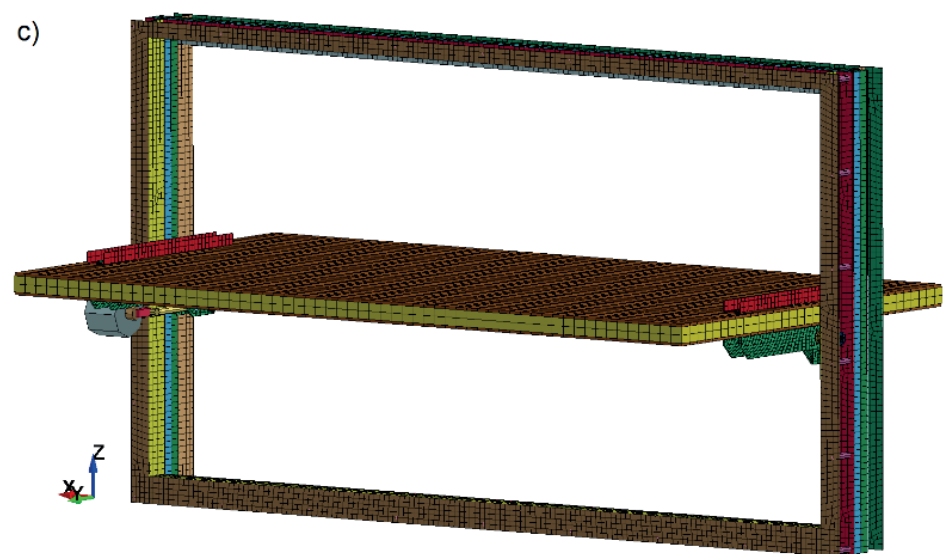

d)

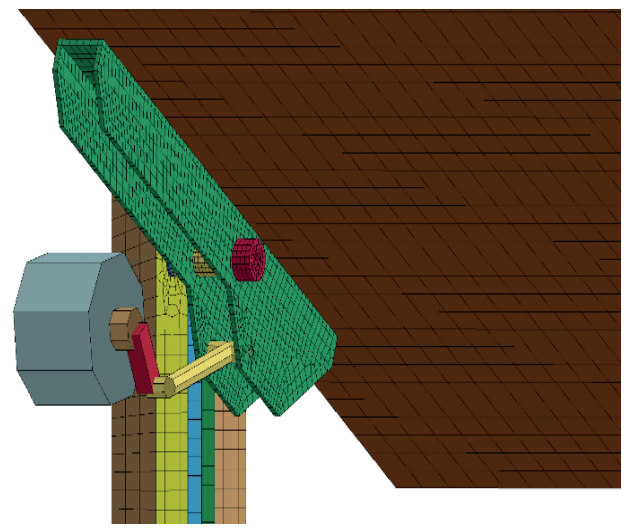

Fig. 3. FEM model of fire damper: a) side view, b) front view, c) isometric view, d) opening lever system

\section{BOUNDARY CONDITIONS}

Using the finite elements method, two events were modelled:

1) fire damper closling in normal service conditions (without earthquake),

2) fire damper closing in case of emergency event, that is after the earthquake episode.

Fire damper closing in normal service conditions consists of two periods:

1) gravity application to the whole structure in 2 seconds,

2) damper closing in 20 seconds, that is from second 2 to 22 of simulation.

Fire damper closing after the earthquake consist of 3 stages:

1) gravity application to the whole structure in 2 seconds,

2) an earthquake that lasts for 13 seconds, from second 2 to 15 of simulation,

3) damper closing in 20 seconds, from second 15 to 35 of simulation.

a)

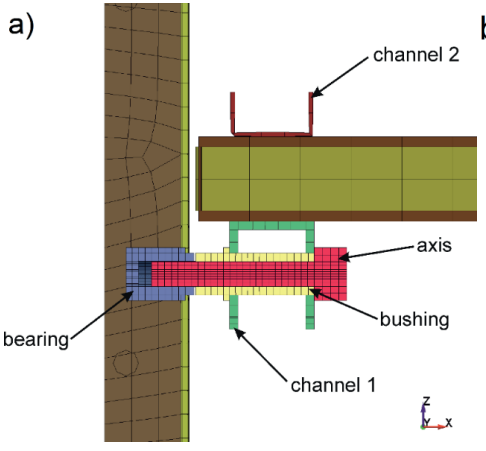

b)

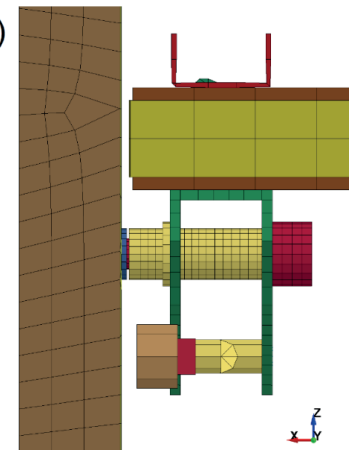

Fig. 4. Model of fire damper bearing

The above described simulation stages are presented in Fig. 5. In the history of vertical component $Z$, which is in the direction of gravity action, all three stages are visible: (1) the increase of acceleration during the application of earth gravity, (2) the stage of earthquake, and (3), the stage of constant acceleration equal to the gravitational acceleration in the time of fire damper closing. During stages 1 and 2, the rotation of motor arm is blocked. In stage 3 , the rotation is being freed and angular acceleration is applied to the arm. Its constant value guarantees damper closing in 20 seconds. 


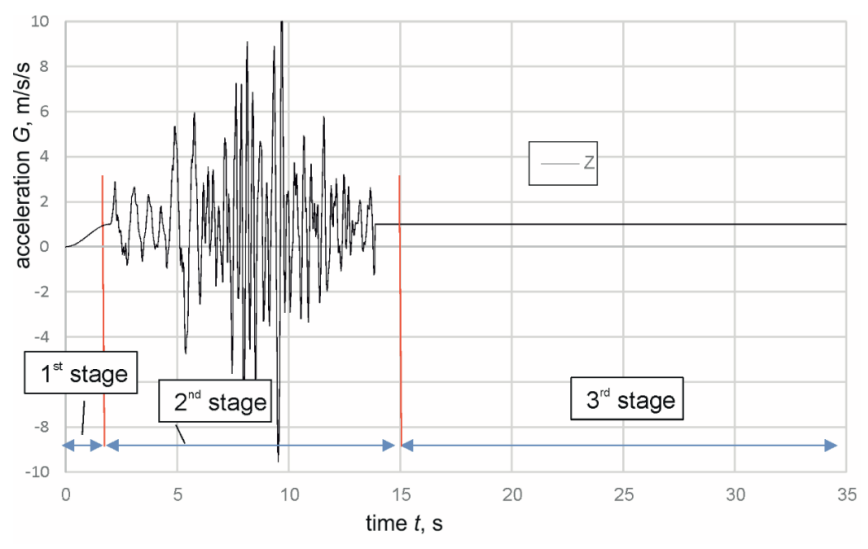

Fig. 5. Three stages of loadings application

\section{MATERIAL MODELS}

In order to gather the information on permanent deformations of the construction, material models including plasticity were assumed for metal parts. From among the models including plasticity in LS-DYNA, a commonly used model bearing the name of MAT_PIECEWISE_LINEAR_ PLASTICIT was selected. Only for the plate made of fire resistant material characterized by the lack of plastic deformations, the linear elastic model MAT_ELASTIC was selected. The material parameters of the applied models are given in Tab. 4.

Tab. 4. Material models and their parameters

\begin{tabular}{|c|c|c|c|c|c|}
\hline Material grade & $\begin{array}{c}\text { Exemplary } \\
\text { application }\end{array}$ & Model type & $\begin{array}{c}\text { Young's } \\
\text { modulus } E \\
{[\mathrm{GPa}]}\end{array}$ & $\begin{array}{c}\text { Yield stress } S_{y} \\
{[\mathrm{MPa}]}\end{array}$ & $\begin{array}{c}\text { Ultimate tensile } \\
\text { strength } \\
S_{u}[\mathrm{MPa}]\end{array}$ \\
\hline S220GD & Sheets & bilinear & 190 & 220 & 300 \\
\hline S355 & Axes, C-sections, pin & bilinear & 190 & 345 & 470 \\
\hline CuSn8 & Bearings bushings & bilinear & 190 & 280 & 450 \\
\hline PROMATECT $^{\infty}-\mathrm{H}$ & Fire resistant plate & linear & 4.2 & & 4.8 \\
\hline
\end{tabular}

The key element of the construction, in view of the fire damper rotation, is the bearing axis made of 1.4306 grade steel. On the basis of preliminary calculations, it was determined that strain rates acting in this element reach values of about $0.09 \mathrm{~s}^{-1}$ (Fig. 6). These are the values which can influence plastic deformation of the element [16].

The influence of strain rate on additional hardening was checked using the Johnson-Cook model ([17]):

$$
\sigma_{y}=\left(A+B \cdot \varepsilon_{p l}^{n}\right)\left(1+C \cdot \ln \frac{\dot{\varepsilon}}{\dot{\varepsilon}_{0}},\right)
$$

where: $A$ - yield stress, $B, n$, - hardening parameters, $C$ strain rate sensitivity parameter, $\varepsilon_{p l}$ - effective plastic strain, - strain rate, - strain rate in case of static test.

For the Johnson-Cook model, the material parameters of $1.4306(304 \mathrm{~L})$ grade steel were taken from [18]. They are
This value was assumed significant for the part which decides of proper fire damper closing. Its damage would result in lack of rotation possibility. Thus, the Johnson Cook model was also assumed for the axis in

equal to: $A=110 \mathrm{MPa}, B=1500 \mathrm{MPa}, n=0.36, C=0.014$. The function that describes the value of additional hardening related to the influence of strain rate is the function in second bracket of (1). After introducing the parameters, we get:

$$
\begin{aligned}
& \left(1+C \cdot \ln \frac{\dot{\varepsilon}}{\dot{\varepsilon}_{0}}\right)= \\
& =\left(1+0.014 \cdot \ln \frac{0.09}{0.001}\right)= \\
& =1.06 .
\end{aligned}
$$

rate of the bearing axis can be estimated as equal to $6 \%$.

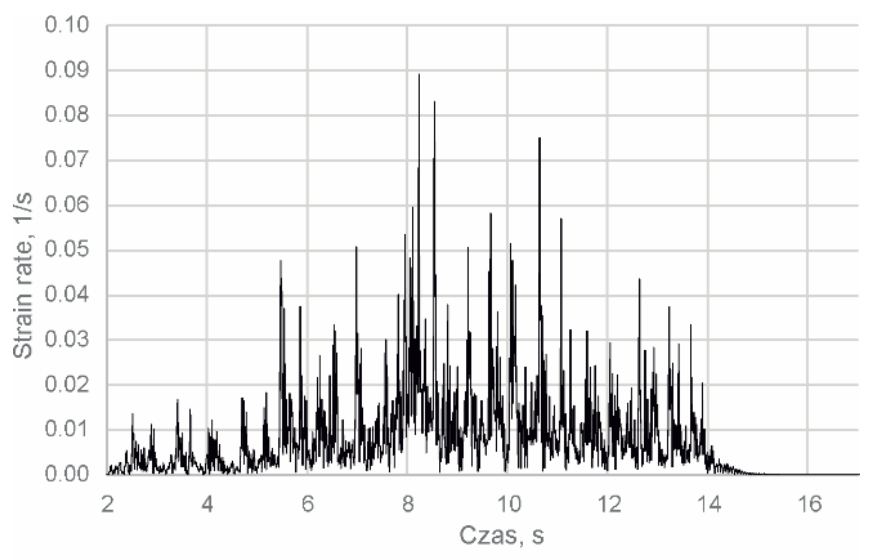

Fig. 6. Equivalent strain rate of bearing axis

LS-DYNA software. Its simplified variant neglects the influence of temperature: MAT_SIMPLIFIED_JOHNSON_COOK.

On the basis of KTA standard [11], 4\% damping factor for all parts was assumed.

\section{MECHANICAL PROPERTIES ANALYSIS AND BOUNDARY CONDITIONS VERIFICATION}

The results of the performed calculations have the form of time-histories of stresses and strains of all elements of the fire damper. The results are presented in two points, regarding to: 1) fire damper capability to resist service loadings and structure's integrity,

2) fire damper capability to stay operative after the earthquake. 


\section{FIRE DAMPER CAPABILITY TO RESIST SERVICE LOADINGS AND STRUCTURE'S INTEGRITY}

In the charts below (Fig. 7, Fig. 8, Fig. 9, Fig. 10), the equivalent Huber-von Mises stress history is presented for the most stressed construction elements. In each of the charts, the stress history is presented for elements made of the same material. For better look on the stress level, the values of yield stress and ultimate tensile strength are also shown. Above the charts, the loading history in the form of one acceleration component is also shown.

The chart analysis shows that the yield stress is exceeded in some parts (Fig. 7, Fig. 8). However, none of these elements has been damaged.

Exceeding the yield stress appears in the axis made of 1.4306 steel and in the bearing sleeve made of S355 steel (Fig. 10). In the plastic strain history chart, permanent deformation of these parts, occurring at the most intensive moment of earthquake, is shown. The values of strain are not high, they reach $0.2-0.45 \%$. But there is a question if they affect proper operation of the fire damper. The answer to that question is presented in the next point.

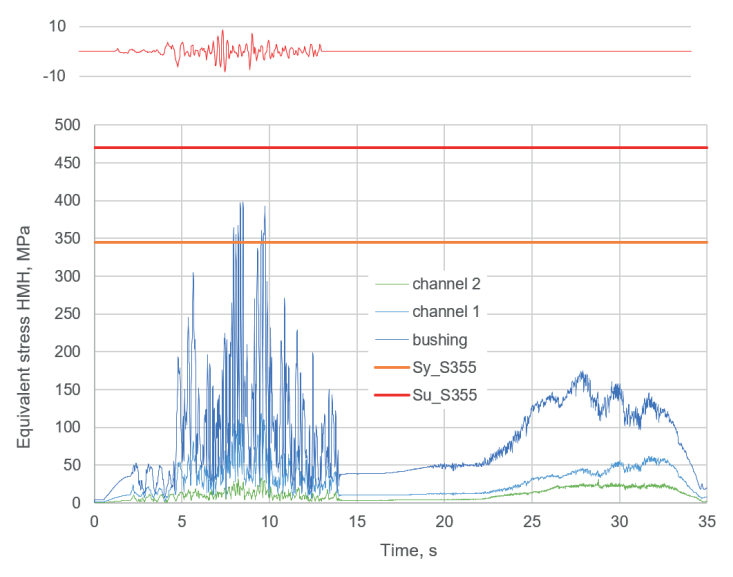

Fig. 7. Equivalent stress history in parts made of S355 steel

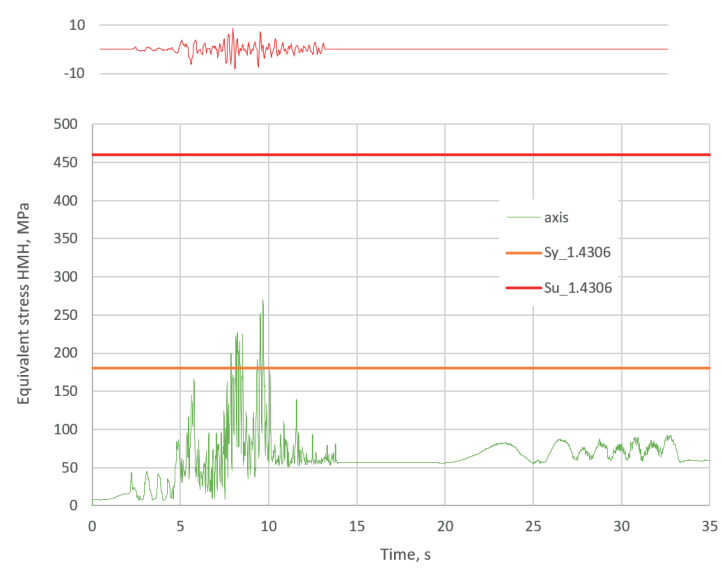

Fig. 8. Equivalent stress history in parts made of 1.4306 steel

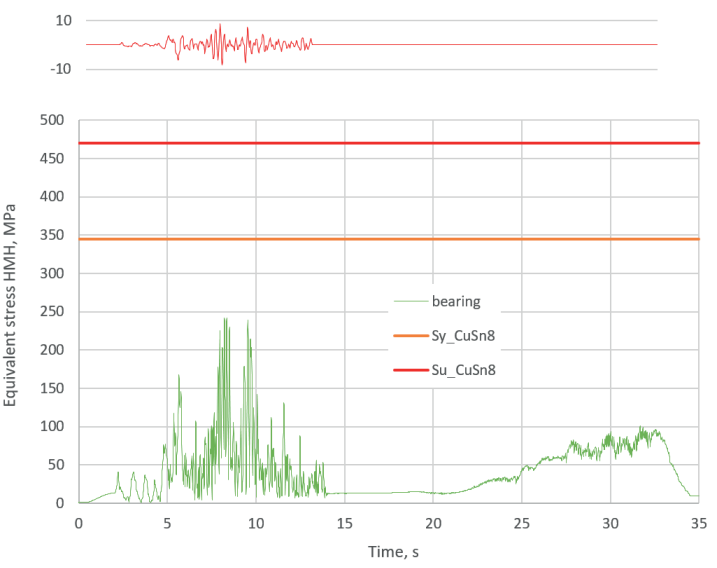

Fig. 9. Equivalent stress history in parts made of CuSn8 bronze

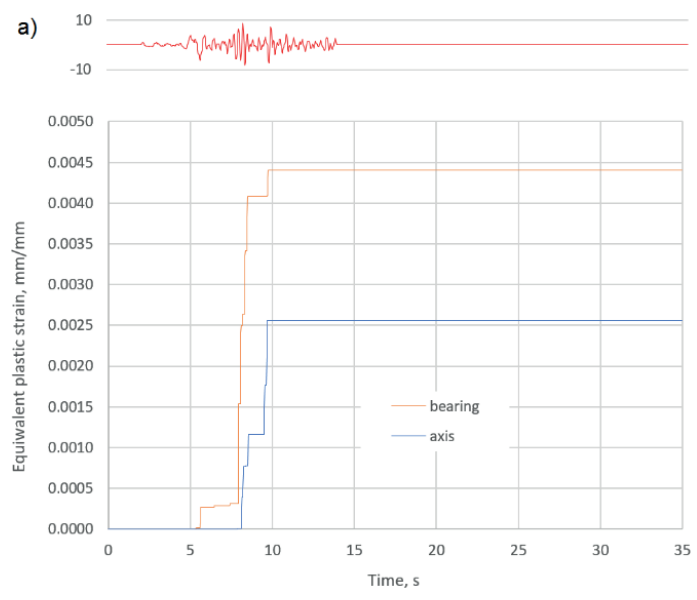

Fig. 10. Equivalent plastic strain history in bearing and axis

\section{FIRE DAMPER FUNCTIONALITY AFTER EARTHQUAKE}

The capability to close hermetically decides whether the fire damper is functional. In order to check it, the history of the torque required to close the damper before and after the earthquake was analysed.

Fig. 11 presents the chart of motor torque required to close the fire damper in conditions preceding the earthquake. The achieved results are recommendations for proper selection of the motor.

Fig. 12 a shows the motor torque required to keep the damper open during the application of earth gravity (stage I) and earthquake (stage II), as well as the torque required to close the damper after the earthquake (stage III).

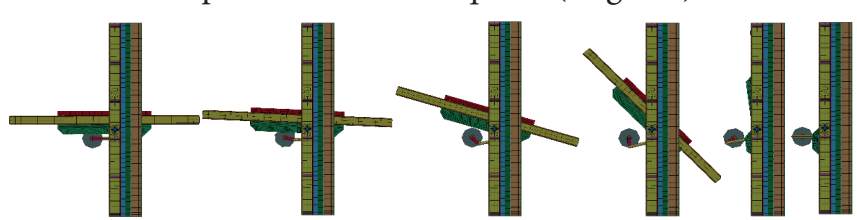




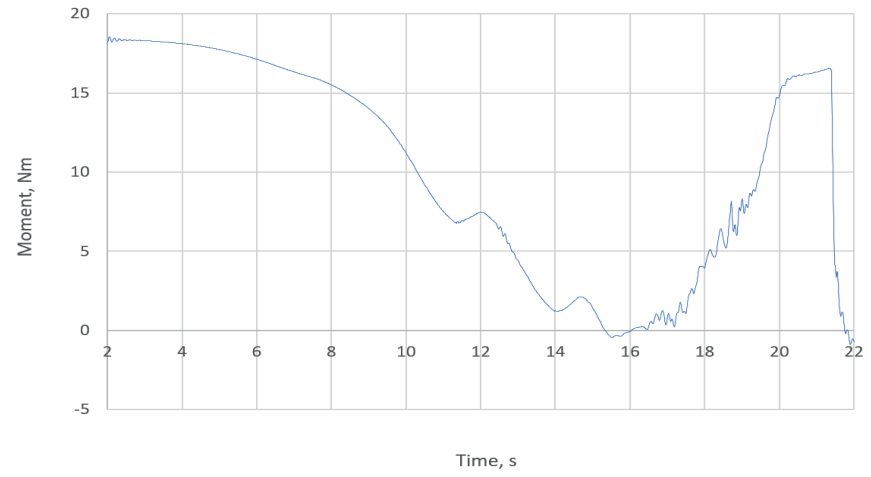

Fig. 11. Motor torque history in the simulation without earthquake

Comparing the period of fire damper closing without earthquake (Fig. 11) and the analogous period of closing after the earthquake (Fig. 12 b), one can notice that in both cases the motor moment reaches similar values. Thus, the presence of plastic deformations does not block damper's ability to close.

Due to the presence of permanent deformations it was checked whether the fire damper has closed hermetically. In Fig. 13, the contact of the fire damper with the frame at second 35 is shown. The change of the distance between the damper and the frame was measured in the middle of the frame's longest side and in its upper and lower part (Fig. 14).
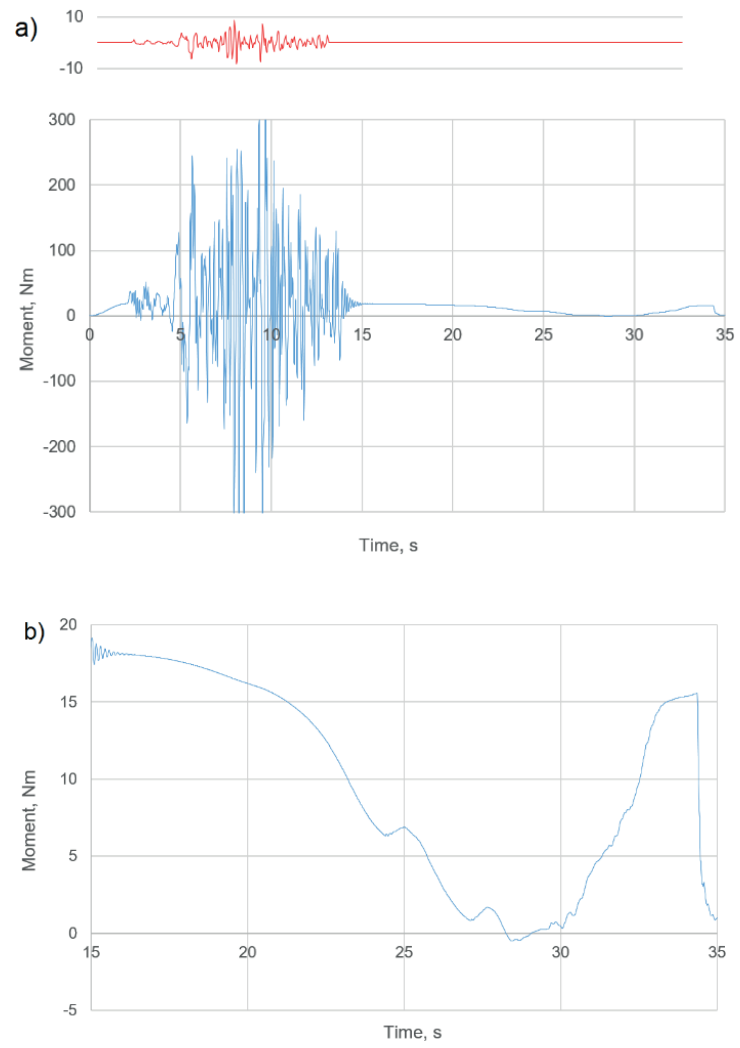

Fig. 12. Motor torque history in the simulation including the earthquake: a) full history, b) torque in stage III, during dumper closing

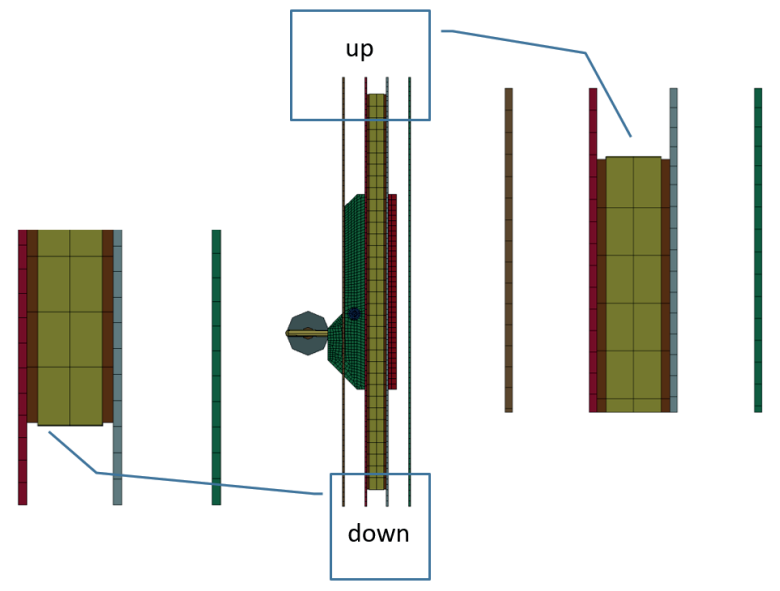

Fig. 13. Illustration of hermetic closing of fire damper

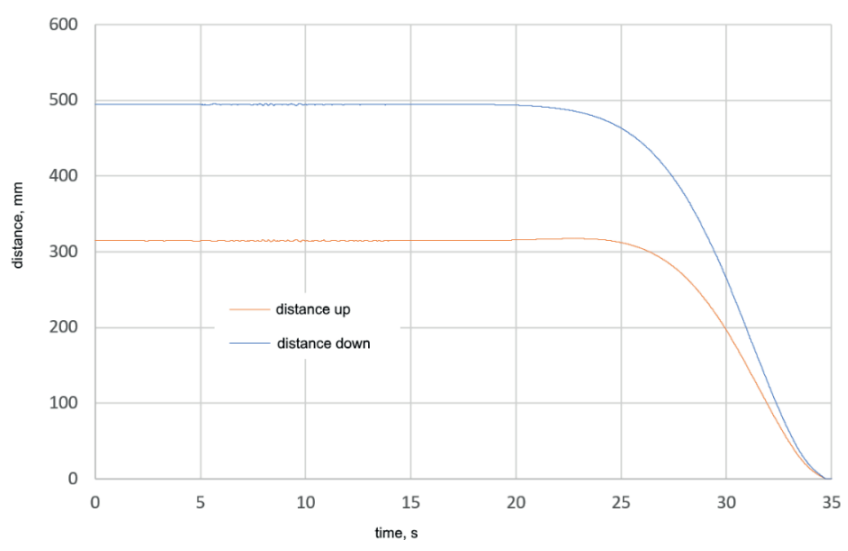

Fig. 14. Distance between fire damper and frame in upper and lower part

\section{CONCLUSIONS}

1) Modification of recordings to fit into the Design Spectrum by Direct Scaling method allowed to show potentially weak links, due to loading caused by the earthquake.

2) LS-DYNA was used to calculate the dynamic time history of a complex construction in earthquake loading conditions. A rich library of material models enabled to capture the strain rate dependent material behaviour. Fire damper operation with the presence of permanent deformation was simulated thanks to effective modelling in the LS-DYNA software.

3) From the dynamic gravity and seismic loading time history analysis, performed using the Finite Element Method, the designers received data on stress levels of individual parts of the construction during the fire damper closing process.

4) Some of the damper parts exhibit plastic deformations caused by accelerations taking place during the earthquake. However, the equivalent stress does not reach strength limits for the used materials in any of the construction elements. 
Despite the presence of plastic strains in some elements, the fire damper loaded with the earthquake remains functional. The dumper closes hermetically within 20 seconds.

\section{ACKNOWLEDGMENTS}

The paper refers to the research financed by the National Centre for Research and Development (NCBiR) in the framework of the project POIR.01.01.01-00-1422/15

\section{REFERENCES}

1. Kozak, J.: Elastic protection coatings for ship fuel tanks, intended for the increasing of environment protection level. Polish Maritime Research, 15, (2008).

2. Dobrzyńska, R.: Selection of outfitting and decorative materials for ship living accommodations from the point of view of toxic hazard in the initial phase of fire progress. Polish Maritime Research, 16, (2009).

3. Skibicki, D., Sempruch, J., Pejkowski, Ł.: Model of nonproportional fatigue load in the form of block load spectrum. Materwiss. Werksttech. 45, 68-78 (2014).

4. Pejkowski, Ł., Skibicki, D.: Criteria Evaluation for Fatigue Life Estimation under Proportional and Non-Proportional Loadings. Mater. Sci. Forum. 726, 189-192 (2012).

5. Design principles - technical safety. NORSOK S-DP-001.

6. Macgillivray, H.: The Development of Standards for Instrumented Charpy Testing. 1-34 (2008).

7. Stephens, R.I., Fatemi, A., Stephens, R.R., Fuchs, H.O.: Metal Fatigue in Engineering. Wiley (2000).

8. Żyliński, B.: Finite element local analysis of wave slamming on offshore structure. Polish Maritime Research, 1, 8-12 (2009).

9. Augustyniak, M., Porembski, G.: FEM strength analysis of sandwich panels for ship structure applications. Polish Maritime Research, S 1, 24-26 (2006).

10. Bogdaniuk, M., Górecki, Z., Brzóska, M.: FEM analysis of ultimate strength of steel panels. Polish Maritime Research, S 1, 21-23 (2006).

11. Design of Nuclear Power Plants against Seismic Events; Part 4: Components. Nucl. Saf. Stand. Comm. (1996).

12. www.earthquake.usgs.gov; date accessed 2017-10-10.

13. Jia, J.: Modern Earthquake Engineering - Offshore and Land-based Structures. Springer-Verlag GmbH Germany (2017).
14. ASCE 7-95: Minimum design loads for buildings and other structures. Am. Soc. Civ. Eng. ASCE, NY. (1995).

15. Benoit, S.C.: Seismic Design for Buildings. U.S. Army Corps Eng. 829 (2005).

16. Stopel, M., Skibicki, D.: Determination of Johnson-Cook model constants by measurement of strain rate by optical method. AIP Conf. Proc. 1780, (2016).

17. Livermore Software Technology Corporation, LS-Dyna Keyword User's Manual, volume II - Volume II R7.1, Materials \& Design, (2014).

18. Xue, Q., Nesterenko, V.F., Meyers, M.A.: Evaluation of the collapsing thick-walled cylinder technique for shear-band spacing. Int. J. Impact Eng. 28, 257-280 (2003).

\section{CONTACT WITH THE AUTHOR}

\section{Dariusz Skibicki}

e-mail:dariusz.skibicki@utp.edu.pl UTP University of Science and Technology

Kaliskiego 7

85-796 Bydgoszcz

Poland 